\title{
Associations between socioeconomic status and chronic kidney disease: a meta-analysis
}

\author{
Xiaoxi Zeng, ${ }^{1,2}$ Jing Liu, ${ }^{1}$ Sibei Tao, ${ }^{1}$ Hyokyoung G Hong, ${ }^{3}{ }^{2} \mathrm{Li}^{4}{ }^{4}$ Ping Fu ${ }^{1,2}$
}

- Additional material is published online only. To view please visit the journal online (http://dx.doi.org/10.1136/ jech-2017-209815)

'Division of Nephrology, Kidney Research Institute, West China Hospital of Sichuan University, Chengdu, China

${ }^{2}$ West China Biomedical Big Data Center, Sichuan University, Chengdu, China

${ }^{3}$ Department of Statistics and Probability, Michigan State University, East Lansing, Michigan, USA

${ }^{4}$ Department of Biostatistics, University of Michigan, Ann Arbor, Michigan, USA

Correspondence to Professor Ping Fu, Division of Nephrology, Kidney Research Institute, West China Hospital of Sichuan University, Chengdu, Sichuan 610041, China;

fupinghx@163.com

$\mathrm{XZ}$ and JL contributed equally.

Received 4 August 2017 Revised 22 November 2017 Accepted 6 January 2018

Published Online First

2 February 2018

Check for updates

To cite: Zeng X, Liu J, Tao S, et al. J Epidemiol Community Health 2018:72:270-279.

\begin{abstract}
Background Socioeconomic status (SES) has long been conjectured to be associated with the incidence and progression of chronic kidney disease (CKD), but few studies have examined this quantitatively. This metaanalysis aims to fill this gap.
\end{abstract}

Methods A systematic literature review was performed using Medline and EMBASE to identify observational studies on associations between SES and incidence and progression of CKD, published between 1974 and March 2017. Individual results were meta-analysed using a random effects model, in line with Meta-analysis of Observational Studies in Epidemiology guidelines.

Results In total, 43 articles met our inclusion criteria. CKD prevalence was associated with several indicators of SES, particularly lower income (OR 1.34, 95\% CI (1.18 to 1.53$\left.), P<0.001 ; I^{2}=73.0 \%, P=0.05\right)$; lower education (OR $1.21,95 \% \mathrm{Cl}(1.11$ to 1.32$), P<0.001 ; I^{2}=45.20 \%$, $\mathrm{P}=0.034) ;$ and lower combined SES (OR 2.18,95\% Cl (1.64 to 2.89), $P<0.001 ; I^{2}=0.0 \%, P=0.326$ ). Lower levels of income, occupation and combined SES were also significantly associated with progression to endstage renal disease (risk ratio (RR) 1.24, 95\% Cl (1.12 to 1.37), $P<0.001 ; I^{2}=66.6 \%, P=0.006 ; R R 1.05,95 \% \mathrm{Cl}$ (1.01 to 1.09), $P=0.012 ; I^{2}=0.0 \%, P=0.796 ;$ and $R R$ $1.39,95 \% \mathrm{Cl}(1.09$ to 1.79$), P=0.009 ;\left.\right|^{2}=74.2 \%$, $\mathrm{P}=0.009)$. Subgroup analyses generally confirmed these results, except in a few cases, such as an inverse association related to particular socioeconomic backgrounds and where results were adjusted by more disease-related risk factors.

Conclusion Lower income was most closely associated with prevalence and progression of CKD, and lower education was significantly associated with its prevalence. Evidence for other indicators was inconclusive.

\section{INTRODUCTION}

Chronic kidney disease (CKD) has become a global issue because of its rapidly increasing prevalence and cost. Its worldwide prevalence ranges from 10.2\% to $13 \%,{ }^{1-3}$ and middle-aged and older people with a history of hypertension or diabetes are more susceptible. ${ }^{4}$ Individuals with lower socioeconomic status (SES) may suffer from unrecognised and untreated CKD as well as end-stage renal disease in both low-income and middle-income countries and developed countries. ${ }^{5-7}$ This may be because of poor access to healthy diets, physical activity, health information and quality healthcare. ${ }^{89}$

Studies on the overall impact of SES on CKD have obvious limitations. SES is a multidimensional concept incorporating material and social factors.
These can differ substantially in their associations and effect size. ${ }^{10}$ In the absence of a uniform definition of SES, various substitutes have been used, including income, education level, occupation, wealth or geographic location. Second, many studies have been confined to particular regions, so the results may not be generalisable. Studies have therefore provided inconsistent results about the magnitude of associations, making it hard to understand the true association between SES and CKD in the general population. Vart et $a l^{5}$ performed a meta-analysis to explore the association between the two, combining estimates from different socioeconomic indicators. However, the mechanisms underlying the association between individual indicators and the onset and progression of CKD need further investigation. We therefore carried out a meta-analysis to examine the association between CKD and several individual indicators of SES.

\section{MATERIALS AND METHODS Study identification}

\section{Information source and search strategy}

Eligible studies on associations between SES and CKD were found by searching four electronic databases: PubMed/Medline, OV/EMBASE, Cochrane Library and Chinese Biomedicine Database from 1974 to March 2017.

Suitable studies involved associations between individual indicators (income, educational attainment or occupation) or a combined index of SES and CKD. ${ }^{11} 12$ Keywords included 'social class', 'socioeconomic status, position, factors', 'income', 'education level', 'occupations', 'chronic kidney disease', 'chronic renal insufficiency', 'chronic kidney failure' and 'chronic renal dysfunction' (see online supplementary material/search strategy). There were no restrictions on languages or countries of publication. Unpublished or non-peer-reviewed articles were excluded. The review complied strictly with Meta-analysis of Observational Studies in Epidemiology guidelines for meta-analyses ${ }^{13}$ (online supplementary table 1 ).

\section{Selection criteria}

Studies were independently screened by two reviewers (JL and ST) using the following criteria:

Inclusion criteria: (1) prospective, retrospective and cross-sectional observational studies; (2) adult population or adult patients diagnosed with CKD; (3) reported associations between at least one determinant of SES and CKD, using adjusted HR, risk ratio (RR) or OR with $95 \%$ CIs or sufficient information to calculate these statistics. 
Exclusion criteria: (1) abstracts, protocols, letters, expert opinions, case reports and reviews; (2) studies on acute renal failure or unrepresented CKD.

Any disagreements were resolved through discussion with another reviewer (XZ).

\section{Data abstraction}

Two independent reviewers (XZ and JL) extracted information about each article including the first author's name, year of publication, country where the study was conducted, type of study design, covariate adjustment degree, sample size, duration of study, indicators of SES (income, education, occupation, combined SES), development and progression of CKD, mean age, sex and risk estimates (OR or RR) with corresponding 95\% CIs.

Measurements of the indicators of SES were all categorised (dichotomised or multicategorised). Combined SES was an indicator which incorporated more than one individual SES indicator. It could be a comprehensive indicator determined by income, education and occupation, ${ }^{14}$ by Index of Multiple Deprivation (IMD) at practice level, ${ }^{15-17}$ or by summary score of area-level SES constructed summing z scores 6-7 census-derived SES indicators. ${ }^{18-20}$ Outcomes were not restricted, but included prevalence, incidence and progression of CKD. To augment between-study comparability using different indicator categories, we also compared the lowest and highest SES categories. The national income level was classified into high, middle or low using the World Bank's 2003 World Development Indicator. ${ }^{21}$ The degree of adjustment was categorised as 'minimal' or 'maximal' depending on whether a model used three or fewer (age, gender or ethnicity), or more than three control covariates. ${ }^{1122}$

\section{Quality assessment}

The quality of studies was assessed using the Newcastle-Ottawa Quality Assessment Scale for cohort or case-control studies, and the Cross-Sectional/Prevalence Study Quality Assessment recommended by the Agency for Healthcare Research and Quality for cross-sectional studies. For Newcastle-Ottawa, the maximum numbers of points awarded in the selection, comparability and exposure (for cohort studies) or outcome (for case-control studies) categories were 4, 2 and 3. The Cross-Sectional/Prevalence Study Quality Assessment contains 11 items covering information source, subject quality, study design and outcome completeness. Each item has 'Yes/No/Unclear' response options: 'Yes' scored one point and 'No' or 'Unclear' zero, and the scores were summed (online supplementary tables 2-4). There is no agreed level of study quality, so we rated it as 'High', 'Moderate' or 'Low', if it had values of 7-9, 4-6 and $0-3$ for cohort or case-control studies, and 8-11, 5-7 and 0-4 for cross-sectional studies.

\section{Statistical analysis}

The estimated associations were obtained using either logistic regressions or Cox proportional hazards models with reported adjusted ORs, HRs or RRs. For studies ${ }^{8} 182023-26$ reporting separate estimates by gender, the risk estimates were pooled (weighted by the inverse of the variance) to obtain summarised estimates.

The meta-analyses used the DerSimonian and Laird $^{27}$ random effects model, which takes into account within-study and between-study variations, stratified by study design ${ }^{28}$ (cohort, case-control or cross-sectional studies). We used adjusted OR and $95 \%$ CIs as metrics for pooled estimates in case-control or cross-sectional studies, and RR and 95\% CIs in cohort studies. To evaluate the heterogeneity, we used Cochrane's Q test. This is statistically significant if $\mathrm{P}<0.1 ; \mathrm{I}^{2}$ below $30 \%$ is defined as unimportant, $30 \%-50 \%$ as moderate, $50 \%-75 \%$ as substantial and $>75 \%$ as considerable heterogeneity. ${ }^{29} 30$

We also used subgroup analyses by geographic area, national income level, different degrees of adjustment for important disease-related risk factors (eg, comorbid conditions, access to healthcare and health behaviours) based on studies that had maximum adjustment, study design, study quality and estimated glomerular filtration rate (eGFR) calculation equation (only for incidence). ORs or RRs were compared using the $\mathrm{Q}$ test to assess the difference.

To evaluate the stability of the results and to test whether a study had excessive influence on the final result, we used a leaveone-study-out sensitivity analysis, ${ }^{31}$ especially for pooled studies with considerable heterogeneity. The presence of publication bias for the hypothesis of an association between low SES and CKD was assessed by funnel plots, coupled by Egger's regression asymmetry test ${ }^{32}$ and Begg's adjusted rank correlation test. ${ }^{33}$ The statistical software was Stata V.13 (Stata, College Station, Texas, USA), and a two-sided $\mathrm{P}<0.05$ was considered statistically significant in all tests.

\section{RESULTS}

\section{Search results}

In total, 3140 articles were identified from electronic databases. After removing duplicates, 2142 unique articles remained, of which 989 did not address the issue of interest, and 898 were not related to the incidence and progression of $\mathrm{CKD}$, leaving 43 articles that met our selection criteria and were therefore included in our meta-analysis (online supplementary figure 1).

The mean age of participants in the studies ranged from 39.7 to 72.7 years. The studies took place in America, Europe, Asia and Africa. Seventeen articles defined CKD as eGFR $<60 \mathrm{~mL} / \mathrm{min} / 1.73 \mathrm{~m}^{2}$, as in the CKD-Modification of Diet in Renal Disease Study. ${ }^{814} 1726$ 34-46 Eight articles used Epidemiology Collaboration (EPI), ${ }^{15} 24$ 47-52 one used Cockcroft-Gault normalised to body surface area equation,$^{53}$ two used creatinine level ${ }^{25} 54$ and the rest eGFR $<45 \mathrm{~mL} / \mathrm{min} / 1.73 \mathrm{~m}^{2} .55$

A total of 29 articles $^{814} 15$ 17 24-26 35-38 40-57 focused on associations between SES and prevalence and incidence of CKD, with a total of 584805 participants. The majority were cross-sectional studies $(\mathrm{n}=21)$ on the association between SES and CKD prevalence. Nineteen studies ${ }^{8} 15172435-3840-4244454749-515457$ were of moderate quality, nine $e^{142526434652535556}$ high and only one $e^{48}$ low (online supplementary tables 2-4). Fourteen articles ${ }^{16} 58-66$ examined the relationship between SES and CKD progression, across more than 6978082 participants (two articles ${ }^{6065}$ did not provide the number of participants). Of these, six studies ${ }^{7166063-65}$ were of moderate quality, and eight ${ }^{18-20} 2358$ 60-62 high. Table 1 shows the characteristics of the studies on prevalence, incidence and progression of CKD. The between-researcher agreement levels on the quality of cross-sectional, case-control and cohort studies were $19 / 21,4 / 5$ and $15 / 17$, respectively. The final quality assessments are shown in online supplementary tables $2-4$.

\section{Overall results}

Associations of SES with CKD prevalence and incidence

A total of 21 articles $^{14} 15172435-38$ 40-44 47-49 51-53 56 57 reporting 24 cross-sectional studies (two articles ${ }^{4352}$ reported five of these), and conducted in the USA, ${ }^{1535-384351525657}$ Europe, ${ }^{1417} 24484952$ 


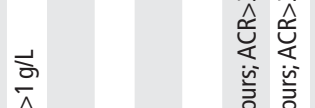

辛辛

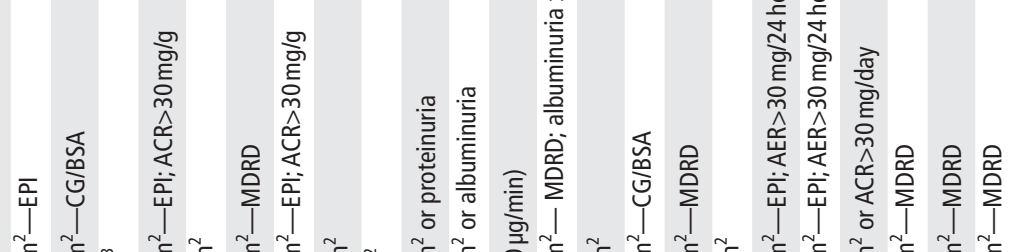

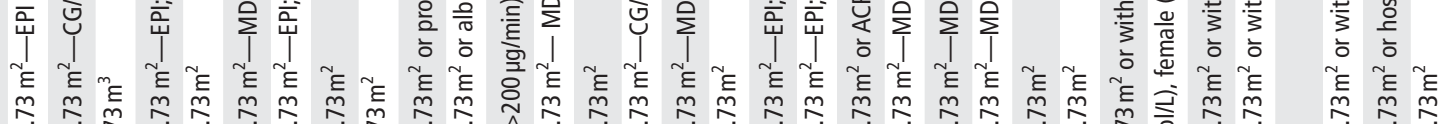

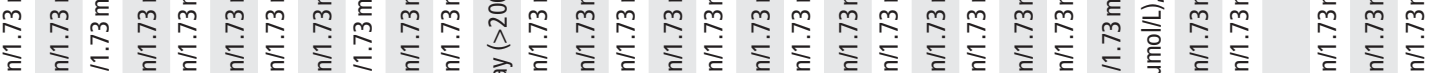

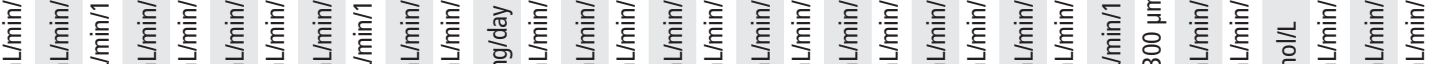

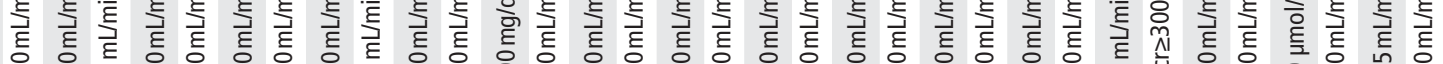

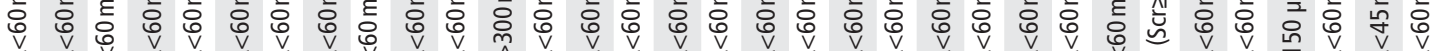

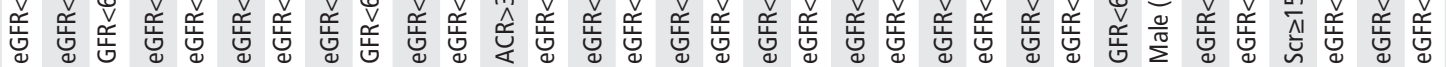

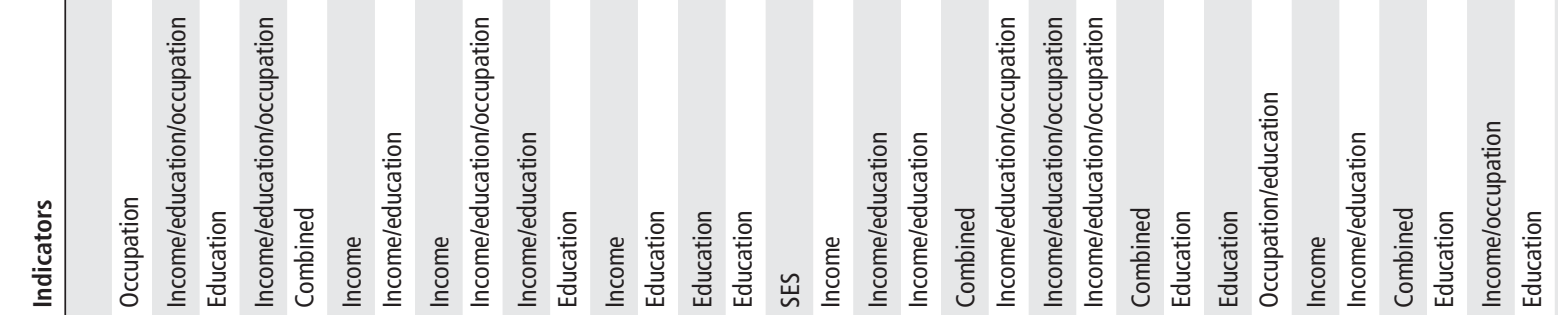

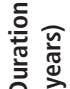

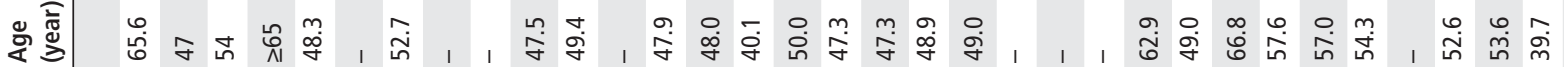

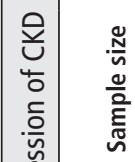

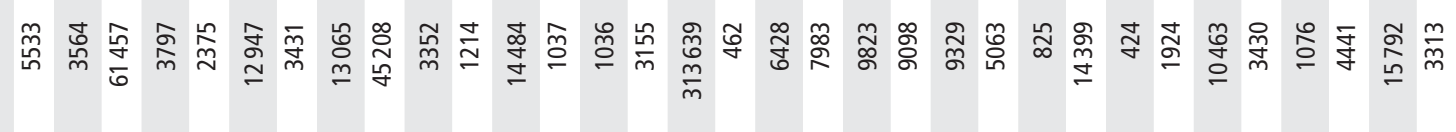

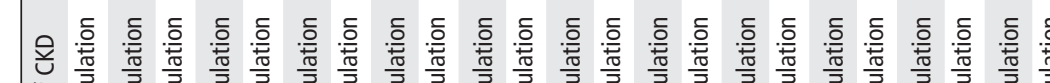

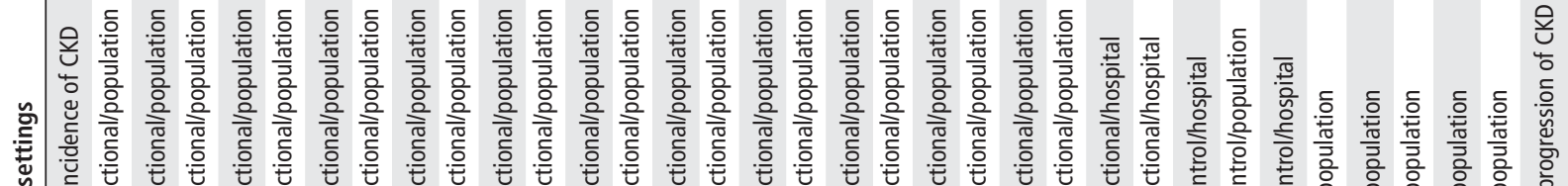

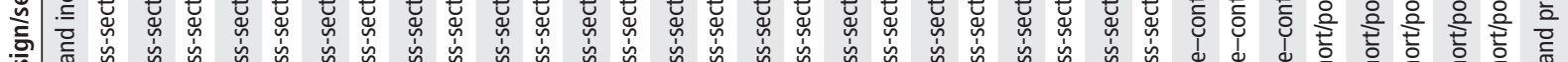

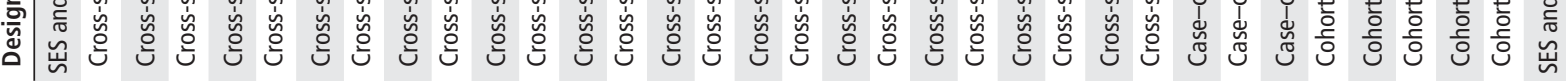

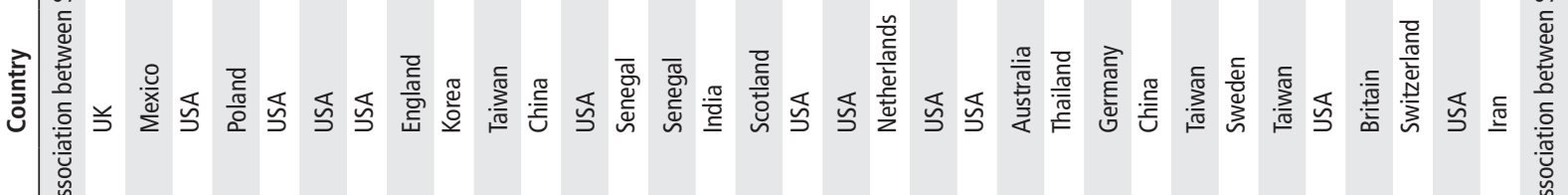

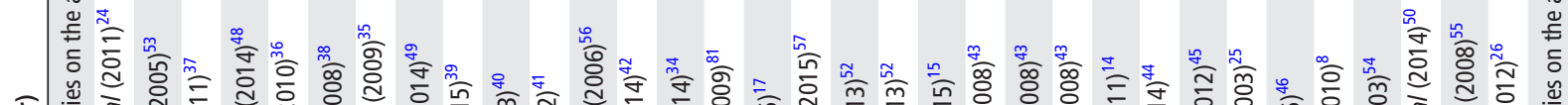

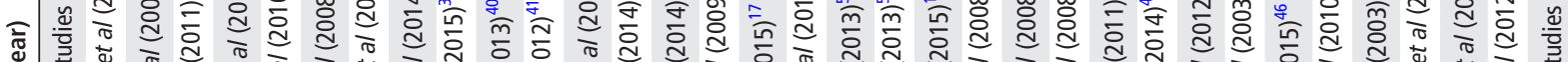

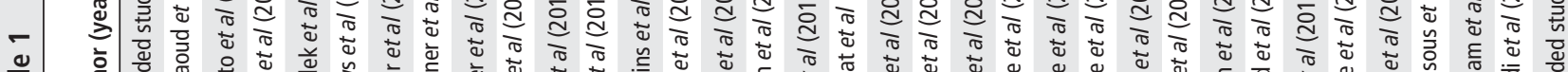

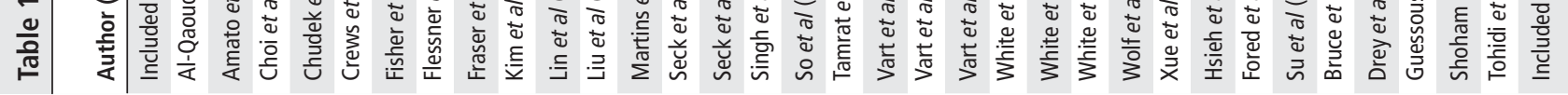




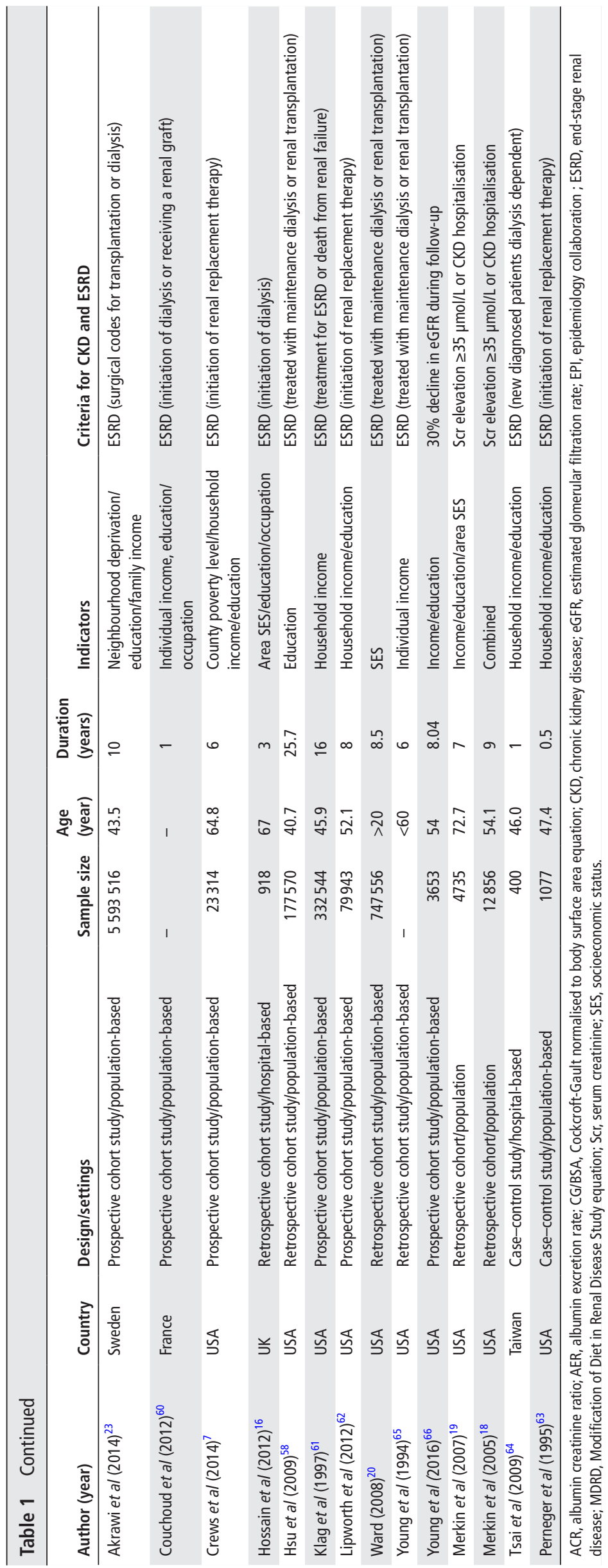



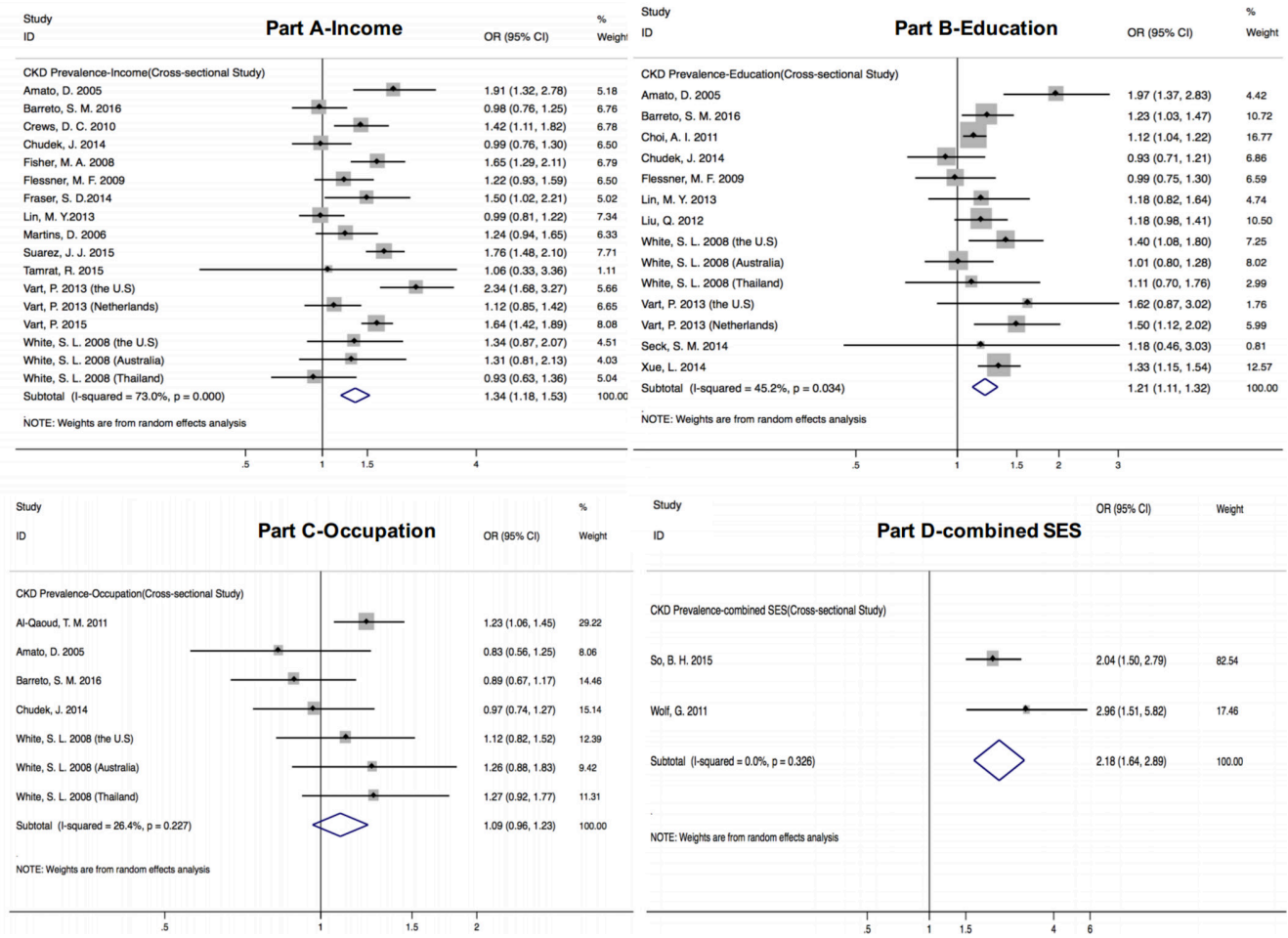

Figure 1 Associations between socioeconomic status (SES) and chronic kidney disease (CKD) prevalence. (Parts A-D demonstrate different associations between SES indicators and CKD incidence in the form of lower income, education level, occupation status and combined SES, respectively.)

Asia, ${ }^{40} 414344$ Africa, ${ }^{42}$ Mexico, ${ }^{53}$ Brazil $^{47}$ and Australia ${ }^{43}$ were published between 2003 and 2016. Most studies focused on associations between CKD prevalence and income $(n=17)$ or education $(n=14)$. Significant associations were found between prevalence and most indicators of SES: lower income (OR 1.34 , 95\% CI (1.18 to 1.53$\left.), \mathrm{P}<0.001 ; \mathrm{I}^{2}=73.0 \%, \mathrm{P}=0.05\right)$; lower education (OR 1.21, 95\% CI (1.11 to 1.32 ), $\mathrm{P}<0.001$; $\left.\mathrm{I}^{2}=45.20 \%, \quad \mathrm{P}=0.034\right)$; and lower combined index $(\mathrm{OR}$ 2.18 , 95\% CI (1.64 to 2.89$), \mathrm{P}<0.001 ; \mathrm{I}^{2}=0.0 \%, \mathrm{P}=0.326$ ) (figure 1A-D). Lower level occupations were not associated with prevalence (OR 1.09, 95\% CI (0.96 to 1.23), $\mathrm{P}=0.168$; $\left.\mathrm{I}^{2}=26.4 \%, \mathrm{P}=0.227\right)$.

Five cohort studies ${ }^{8} \quad \begin{array}{lllll}26 & 50 & 54 & 55 & \text { and three case-control }\end{array}$ studies $^{254546}$ explored the relationship between SES and CKD incidence. Incidence was significantly associated with lower income (RR 1.59, 95\% CI (1.23 to 2.04), $\mathrm{P}<0.01$; $\mathrm{I}^{2}=0.0 \%$, $\mathrm{P}=0.5 / \mathrm{OR} 2.00$, 95\% CI (1.49 to 2.60$), \mathrm{P}<0.001 ; \mathrm{n}=1)$, occupation level (RR 1.72, 95\% CI (1.31 to 2.25), $\mathrm{P}<0.01$; $\mathrm{n}=1 / \mathrm{OR} 1.70,95 \% \mathrm{CI}(1.18$ to 2.45$), \mathrm{P}=0.005 ; \mathrm{n}=1)$ and combined index (RR 1.17, 95\% CI (1.12 to 1.23$), \mathrm{P}<0.01 ; \mathrm{n}=1$ / OR $2.18,95 \%$ CI (1.64 to 2.89$), \mathrm{P}=0.003)$, but had no association with lower educational level (RR 1.16, 95\% CI $(0.82$ to 1.63), $\mathrm{P}=0.4 ; \mathrm{I}^{2}=71.8 \%, \mathrm{P}=0.03 / \mathrm{OR} 2.66,95 \% \mathrm{CI}$ ( 0.57 to 12.43), $\mathrm{P}=0.212 ; \mathrm{I}^{2}=89.5 \%, \mathrm{P}=0.002$ ) (figure 2 ).

The association between SES and CKD progression

Twelve cohort studies ${ }^{7} 1618-202358$ 60-62 6566 provided RRs for the association between CKD progression and indicators of SES, mostly income $(n=7)$ or education $(n=7)$. Progression was significantly associated with lower income (RR 1.24, 95\% CI (1.12 to 1.37$\left.), \mathrm{P}<0.001 ; \mathrm{I}^{2}=66.6 \%, \mathrm{P}=0.006\right)$, lower level occupation (RR 1.05, 95\% CI (1.01 to 1.09), $\mathrm{P}=0.012$; $\left.\mathrm{I}^{2}=0.0 \%, \mathrm{P}=0.796\right)$ and lower combined SES (RR 1.39, 95\% CI
(1.09 to 1.79$\left.), P=0.009 ; \mathrm{I}^{2}=74.2 \%, \mathrm{P}=0.009\right)$. There was no significant association with education (RR $1.11,95 \% \mathrm{CI}(0.94$ to 1.30 ), $\mathrm{P}=0.218 ; \mathrm{I}^{2}=71.3 \%, \mathrm{P}=0.002$ ) (figure $3 \mathrm{~A}-\mathrm{D}$ ). Two casecontrol studies ${ }^{63} 64$ showed significant associations between lower income and CKD progression (OR 3.83, 95\% CI (2.28 to

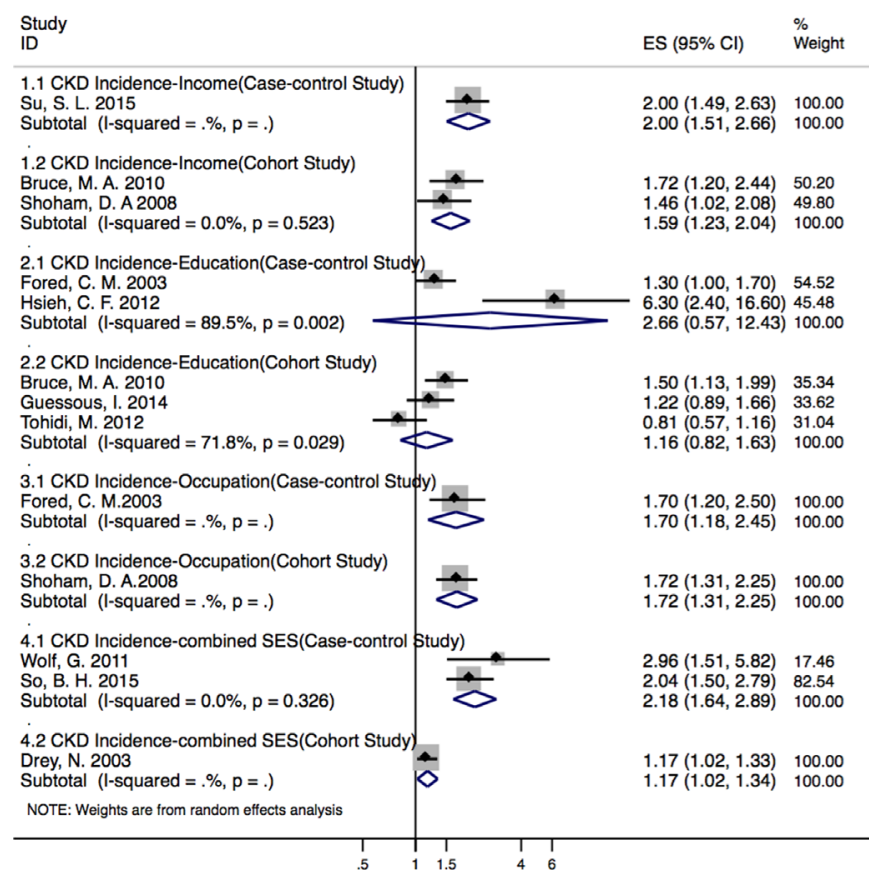

Figure 2 Associations between socioeconomic status (SES) and chronic kidney disease (CKD) incidence (by different study designs with each SES indicator). ES, effect size. 


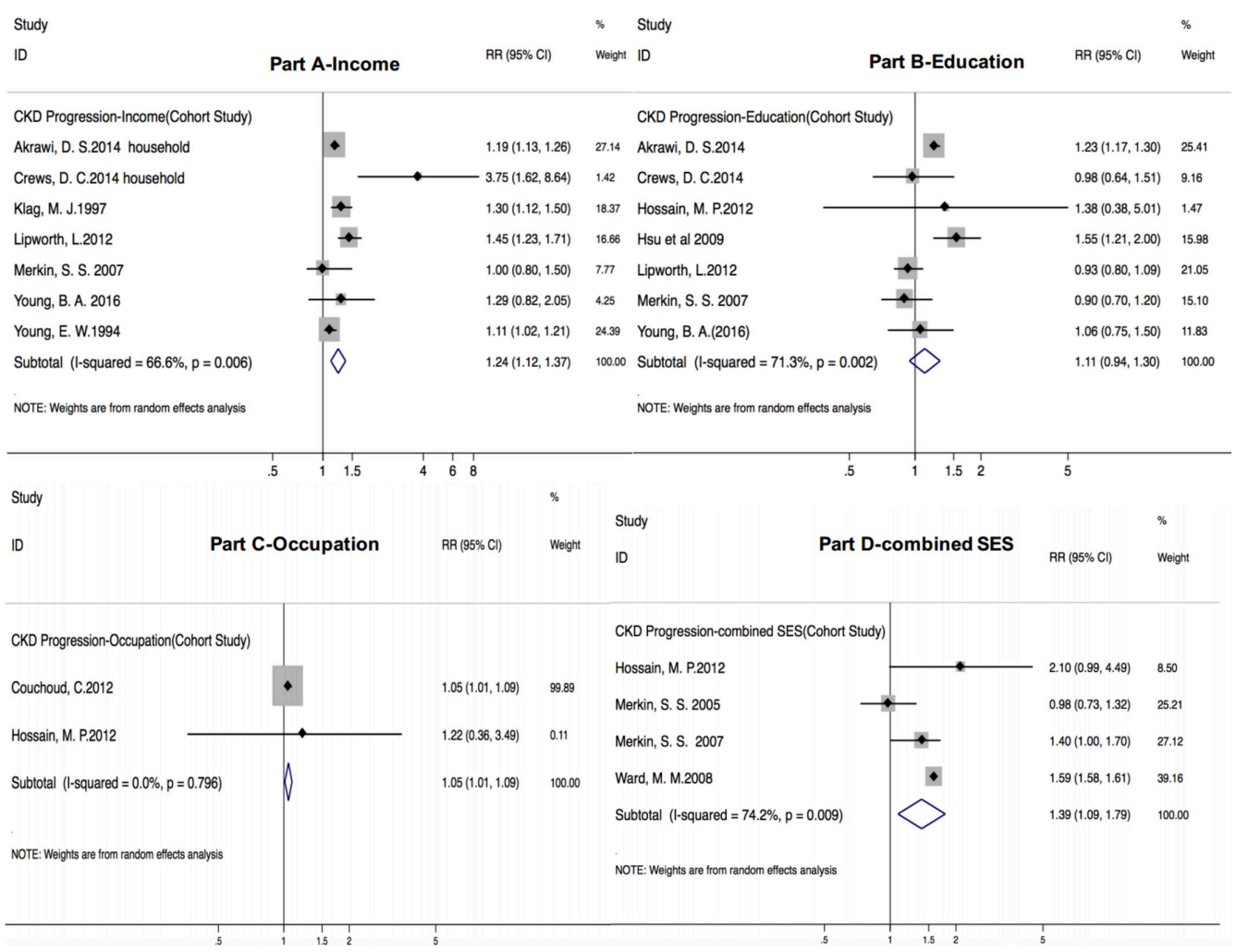

Figure 3 Associations between socioeconomic status (SES) and chronic kidney disease (CKD) progression to end-stage renal disease (ESRD). (Parts A-D demonstrate different associations between SES indicators and CKD progression in the form of lower income, education level, occupation status and combined SES, respectively.) RR, risk ratio.

6.42), $\mathrm{P}<0.001 ; \mathrm{I}^{2}=30.0 \%, \mathrm{P}=0.232$ ). No single studies exerted an obviously excessive influence on the associations.

\section{Subgroup analyses}

The associations between CKD prevalence and progression and the indicators of SES varied across several factors (see table 2). We also planned to use gender but there were insufficient data. When relative estimations were fully adjusted for comorbid conditions, health access and health-related behaviours, the associations between CKD prevalence and lower income and education level were still significant, with lower heterogeneity (income: $\mathrm{OR} 1.46,95 \% \mathrm{CI}$ (1.23 to 1.74 ), $\mathrm{P}<0.001 ; \mathrm{I}^{2}=49.4 \%$, $\mathrm{P}=0.139$; education: $\mathrm{OR} 1.11,95 \% \mathrm{CI}$ (1.03 to 1.20$), \mathrm{P}=0.008$; $\left.\mathrm{I}^{2}=0.0 \%, \mathrm{P}=0.398\right)$. All the significant associations between lower income, education and occupation and SES prevalence were observed in high-income (income: OR 1.49, 95\% CI (1.32 to 1.67), $\mathrm{P}<0.001 ; \mathrm{I}^{2}=50.1 \%, \mathrm{P}=0.024$; education: $\mathrm{OR}$ $1.19,95 \%$ CI (1.06 to 1.34$), \mathrm{P}=0.003 ; \mathrm{I}^{2}=40.7 \%, \mathrm{P}=0.120$; occupation: OR $1.21,95 \% \mathrm{CI}$ (1.06 to 1.38$), \mathrm{P}=0.004 ; \mathrm{I}^{2}=0.0 \%$, $\mathrm{P}=0.849$ ), but not upper middle-income countries (income: OR 1.20, $\mathrm{P}=0.340$; education: $\mathrm{OR} 1.28, \mathrm{P}=0.163$; occupation: OR $0.91, \mathrm{P}=0.293)$. The association between prevalence and education was similar in the USA, Europe and Asia-Pacific Region $(\mathrm{OR}=1.17,1.18,1.21 ; \mathrm{P}=0.783)$, but the association between prevalence and lower income was more marked in the USA than Europe $(\mathrm{OR}=1.55$ vs $1.14 ; \mathrm{P}=0.013)$. The results of studies from the 2000s and 2010s were similar (comparison of ORs from subgroups of 2000 s vs 2010 s in income ( $P=0.809)$, in education ( $\mathrm{P}=0.974)$ and occupation $(\mathrm{P}=0.353))$.

All the cohort studies on the association between SES and disease progression were conducted in high-income countries, and there was a significant association between lower income and progression in several geographic areas (USA: RR 1.27, 95\% CI (1.08 to 1.50), $\mathrm{P}=0.004$; European countries: RR 1.19, $95 \% \mathrm{CI}(1.13$ to 1.26$), \mathrm{P}<0.001)$. The association between lower educational attainment and disease progression in Europe (RR 1.23, 95\% CI (1.17 to 1.30 ), $\mathrm{P}<0.001 ; \mathrm{I}^{2}=0.0 \%, \mathrm{P}=0.861$ ) was statistically significant but inconsistent with the overall trend. If the analysis was limited to studies that fully adjusted for disease-related risk factors, the associations between progression and lower income and education level were insignificant (OR 1.29 vs $1.06, \mathrm{P}=0.276$ vs 0.742 ). More studies were published after 2010, accounting for more than half of the eligible studies on both income and education, with similar results (RR 1.39, 95\% CI (1.11 to 1.74$), \mathrm{P}=0.004$; RR $1.07, \mathrm{P}=0.454)$ with substantial heterogeneity $\left(\mathrm{I}^{2}=75.0 \%, \mathrm{P}=0.007 ; \mathrm{I}^{2}=68.1 \%\right.$, $\mathrm{P}=0.014$ ). (See table 3.)

The publication bias funnel plots and results of Begg's test and Egger's test (online supplementary figures $2.1-2.3,3.1,3.2$ ) showed no publication bias except for studies on the association between income and disease progression (Egger's test $\mathrm{P}=0.05$ ). Publication bias analysis was not possible on other indicators of SES because of the limited number of studies. ${ }^{67}$

\section{DISCUSSION}

This meta-analysis has shown several associations between individual indicators of SES and CKD prevalence and progression. The effect sizes of these associations varied by national income, geographic location and level of adjustment. Lower income and education level were strongly associated with CKD prevalence in high-income countries, except Europe. Disease progression was associated with lower income in the USA and Europe, but the association with lower educational attainment was only significant in Europe. 
Table 2 Pooled OR (from cross-sectional) of CKD prevalence in the lower SES indicators compared with the higher in series of subgroup analyses

\begin{tabular}{|c|c|c|c|c|c|c|c|c|c|}
\hline \multirow[b]{2}{*}{ Subgroup (prevalence) } & \multicolumn{3}{|c|}{ Income } & \multicolumn{3}{|c|}{ Education } & \multicolumn{3}{|c|}{ Occupation } \\
\hline & $\bar{n}$ & OR $(95 \% \mathrm{Cl})$ & $\mathrm{I}^{2}(\mathrm{P})$ & $\mathrm{n}$ & OR $(95 \% \mathrm{Cl})$ & $I^{2}(P)$ & $n$ & OR $(95 \% \mathrm{Cl})$ & $\mathrm{I}^{2}(\mathrm{P})$ \\
\hline Overall & 17 & 1.34 (1.18 to 1.53$)$ & $73.0 \%(0.050)$ & 14 & 1.21 (1.11 to 1.32$)$ & $45.2 \%(0.034)$ & 7 & 1.09 (0.96 to 1.23$)$ & $26.4 \%(0.227)$ \\
\hline \multicolumn{10}{|l|}{ Geographic area } \\
\hline USA & 9 & 1.55 (1.37 to 1.75$)$ & $47.8 \%(0.053)$ & 4 & 1.17 (1.01 to 1.36$)$ & $38.8 \%(0.179)$ & 1 & 1.12 (0.82 to 1.52$)$ & - \\
\hline Europe & 3 & 1.14 (0.93 to 1.41$)$ & $33.3 \%(0.223)$ & 2 & 1.18 (0.74 to 1.88$)$ & $82.0 \%(0.018)$ & 2 & 1.12 (0.89 to 1.41$)$ & $55.0 \%(0.136)$ \\
\hline Asian-Pacific Region & 3 & 1.01 (0.85 to 1.20$)$ & $0.0 \%(0.516)$ & 5 & 1.21 (1.09 to 1.33 ) & $2.6 \%(0.392)$ & 2 & 1.27 (0.99 to 1.62 ) & $0.0 \%(0.975)$ \\
\hline Latin America & 2 & 1.35 (0.70 to 2.59 ) & $88.3 \%(0.003)$ & - & - & - & 2 & 0.87 (0.69 to 1.09 ) & $0.0 \%(0.780)$ \\
\hline Africa & 0 & - & - & 1 & 1.18 (0.46 to 3.03 ) & - & 0 & - & - \\
\hline \multicolumn{10}{|l|}{ Country's income level } \\
\hline High & 12 & 1.49 (1.32 to 1.67$)$ & $50.1 \%(0.024)$ & 6 & 1.18 (1.04 to 1.35$)$ & $46.0 \%(0.099)$ & 3 & 1.21 (1.06 to 1.38$)$ & $0.0 \%(0.8490)$ \\
\hline Upper middle & 3 & 1.20 (0.83 to 1.74$)$ & $79.6 \%(0.007)$ & 3 & 1.28 (0.90 to 1.82$)$ & $81.3 \%(0.005)$ & 3 & 0.91 (0.76 to 1.08 ) & $0.0 \%(0.802)$ \\
\hline Lower middle & 2 & 0.98 (0.81 to 1.17$)$ & $0.0 \%(0.779)$ & 4 & 1.25 (1.13 to 1.39$)$ & $0.0 \%(0.695)$ & 1 & 1.27 (0.92 to 1.76$)$ & - \\
\hline Low & 0 & - & - & 1 & 1.18 (0.46 to 3.03$)$ & - & 0 & - & - \\
\hline \multicolumn{10}{|c|}{ Adjustments for CKD-related risk factors } \\
\hline None & 5 & 1.66 (1.25 to 2.20$)$ & $72.7 \%(0.005)$ & 3 & 1.67 (1.34 to 2.06$)$ & $0.0 \%(0.398)$ & 1 & 0.83 (0.56 to 1.24$)$ & - \\
\hline Health behaviours & 1 & 0.99 (0.76 to 1.30$)$ & - & 1 & 0.93 (0.71 to 1.21$)$ & - & 1 & 0.97 (0.74 to 1.27 ) & - \\
\hline Comorbid conditions & 1 & 1.24 (0.94 to 1.65$)$ & - & 0 & - & - & 1 & 1.23 (1.05 to 1.44$)$ & - \\
\hline +Health behaviours & 7 & 1.20 (0.99 to 1.45$)$ & $74.7 \%(<0.001)$ & 8 & $1.23(1.14$ to 1.33$)$ & $0.0 \%(0.630)$ & 4 & $1.10(0.93$ to 1.30$)$ & $14.3 \%(0.321)$ \\
\hline +Healthcare access & 3 & 1.46 (1.23 to 1.74$)$ & $49.4 \%(0.139)$ & 2 & 1.11 (1.03 to 1.20$)$ & $0.0 \%(0.398)$ & 0 & - & - \\
\hline \multicolumn{10}{|l|}{ Study period } \\
\hline $2000 \mathrm{~s}$ & 7 & 1.35 (1.14 to 1.60$)$ & $42.2 \%(0.109)$ & 5 & 1.24 (0.97 to 1.57 ) & $68.3 \%(0.013)$ & 4 & 1.13 (0.94 to 1.34 ) & $3.2 \%(0.376)$ \\
\hline $2010 \mathrm{~s}$ & 10 & 1.34 (1.11 to 1.62$)$ & $81.6 \%(<0.001)$ & 9 & $1.20(1.10$ to 1.30$)$ & $27.4 \%(0.200)$ & 3 & 1.05 (0.85 to 1.29 ) & $60.0 \%(0.082)$ \\
\hline \multicolumn{10}{|l|}{ CKD definitions } \\
\hline MDRD equation & 9 & 1.24 (1.08 to 1.43$)$ & $40.2 \%(0.099)$ & 9 & 1.16 (1.09 to 1.25$)$ & $9.9 \%(0.352)$ & 3 & 1.21 (1.00 to 1.46$)$ & $0.0 \%(0.83)$ \\
\hline EPI equation & 7 & 1.40 (1.13 to 1.75$)$ & $83.6 \%(<0.001)$ & 4 & 1.23 (0.99 to 1.53 ) & $55.0 \%(0.084)$ & 3 & 1.05 (0.85 to 1.29 ) & $60.0 \%(0.082)$ \\
\hline CG/BSA equation & 1 & 1.91 (1.32 to 2.78$)$ & - & 1 & 1.97 (1.37 to 2.83 ) & - & 1 & 0.83 (0.56 to 1.25$)$ & - \\
\hline
\end{tabular}

CG/BSA, Cockcroft-Gault normalised to body surface area equation; CKD, chronic kidney disease; EPI, epidemiology collaboration equation; MDRD, Modification of Diet in Renal Disease Study; SES, socioeconomic status.

Interactions between indicators of SES may bring statistical artefacts, especially for parameters with significant associations such as income and education level. A previous study clarified that indicators of SES are only modestly correlated with each other, and we found that income was still associated with CKD prevalence even after full adjustment for other indicators. Indicators of SES are therefore not directly comparable and may be independently associated with health outcomes to some degree.

The association between lower income and CKD prevalence could be attributed to food insufficiency, inadequate nutritional intake, exposure to environmental toxins, infection and/or inflammation, distress or anxiety over income disadvantage, inadequate health insurance and poorer access to quality healthcare services. ${ }^{1543535}$ Inadequate diet and unhealthy lifestyles were likely to be associated with obesity, diabetes mellitus and hypertension, which may be causally linked to kidney disease. ${ }^{35} 68$ There was a significant association in high-income but not upper middle-income countries. This might be partly explained by differences in healthcare and insurance systems. ${ }^{25}$ Socialised medicine systems in some upper middle-income countries might attenuate the association between income and CKD. Income-related and education-related inequalities might also be smaller in countries providing relatively generous universal welfare, such as Scandinavian countries. ${ }^{69}$ The effect size was larger in the USA than in Europe, which might be partly because of stricter guidelines on comorbidity management in Europe, ${ }^{70}$ and a publicly financed healthcare system in most European Union member states. ${ }^{71}$

The association between lower educational attainment and CKD was complex, as it may be mediated by behavioural risk factors. For example, several studies ${ }^{72-74}$ have found that lower education is linked to various CKD-related behavioural risk factors (smoking and alcohol, poor diet planning ability and lack of physical activity), and chronic conditions leading to secondary CKD, such as diabetes and hypertension. Better education enables individuals to make better healthcare decisions and obtain better access to healthcare interventions and plans, ${ }^{75}$ so helps to improve general health in individuals and their children. ${ }^{37}$ Interestingly, awareness of CKD is not linked to education level. For example, one study ${ }^{35}$ found that the majority of subjects with more than high school education were unaware of their CKD status

Only a few studies have examined the association between occupation and CKD, and occupation categories were not standard, but each OR or RR maximised the comparability. Individuals with lower level occupations were more likely to be exposed to hazardous working conditions, ${ }^{25}$ and blue collar workers were more likely to be obese than white collar workers. ${ }^{687677}$ Obesity is a significant risk factor for diabetes and hypertension, ${ }^{78}$ and in turn to CKD. The potential mechanisms linking lower level occupations to CKD onset included fewer nephrons, nephrotoxins (analgesics), and poor diet and health behaviours. ${ }^{55}$ 
Table 3 Pooled RR (from cohort studies) of CKD progression in the lower SES compared with the higher in series of subgroup analyses

\begin{tabular}{|c|c|c|c|c|c|c|}
\hline \multirow[b]{2}{*}{ Subgroup (progression) } & \multicolumn{3}{|c|}{ Income } & \multicolumn{3}{|c|}{ Education } \\
\hline & $\mathrm{n}$ & RR $(95 \% \mathrm{Cl})$ & $\mathrm{I}^{2}$ & $\mathrm{n}$ & RR $(95 \% \mathrm{Cl})$ & $\mathrm{I}^{2}$ \\
\hline Overall & 7 & $1.24(1.12$ to 1.37$)$ & $66.6 \%(0.006)$ & 7 & $1.11(0.94$ to 1.30$)$ & $71.3 \%(0.002)$ \\
\hline \multicolumn{7}{|l|}{ Geographic area } \\
\hline USA & 6 & $1.27(1.08$ to 1.50$)$ & $72.5 \%(0.003)$ & 5 & 1.06 (0.86 to 1.32$)$ & $71.3 \%(0.002)$ \\
\hline Europe & 1 & 1.19 (1.13 to 1.26$)$ & - & 2 & $1.23(1.17$ to 1.30$)$ & $0.0 \%(0.861)$ \\
\hline Asia & 0 & - & - & 0 & - & - \\
\hline \multicolumn{7}{|l|}{ Country's income group } \\
\hline High & 7 & 1.24 (1.12 to 1.37$)$ & $66.6 \%(0.006)$ & 7 & $1.11(0.94$ to 1.30$)$ & $75.6 \%(0.001)$ \\
\hline Middle & 0 & - & - & 0 & - & - \\
\hline \multicolumn{7}{|l|}{ SES-related risk factor adjustments } \\
\hline None & 3 & 1.19 (1.03 to 1.37$)$ & $78.4 \%(0.010)$ & 3 & $1.23(1.16$ to 1.29$)$ & $0.0 \%(0.579)$ \\
\hline Health behaviours & 0 & - & - & 1 & 0.90 (0.69 to 0.18$)$ & - \\
\hline Comorbid conditions & 1 & $1.45(1.23$ to 1.71$)$ & - & 1 & $1.11(0.93$ to 1.33$)$ & $75.6 \%(0.001)$ \\
\hline +Health behaviours & 2 & $1.18(0.93$ to 1.52$)$ & $54.6 \%(0.138)$ & 1 & $0.93(0.80$ to 1.09$)$ & - \\
\hline +Healthcare access & 1 & 1.29 (0.82 to 2.04$)$ & - & 1 & $1.06(0.75$ to 1.50$)$ & - \\
\hline \multicolumn{7}{|l|}{ CKD progression definitions } \\
\hline Initiation of RRT & 4 & $1.26(1.10$ to 1.45$)$ & $80.4 \%(0.002)$ & 5 & $1.16(0.96$ to 1.41$)$ & $75.2 \%(0.003)$ \\
\hline Initiation of RRT or death from renal failure & 1 & $1.30(1.12$ to 1.50$)$ & B & 0 & - & - \\
\hline Scr elevation & 1 & $1.00(0.73$ to 1.37$)$ & - & 1 & 0.90 (0.69 to 0.18$)$ & \\
\hline $30 \%$ eGFR decline & 1 & 1.29 (0.82 to 2.04$)$ & - & 1 & $1.06(0.75$ to 1.50$)$ & - \\
\hline \multicolumn{7}{|l|}{ Study design } \\
\hline Prospective & 6 & $1.26(1.13$ to 1.40$)$ & $70.1 \%(0.005)$ & 4 & 1.07 (0.88 to 1.29$)$ & $76.0 \%(0.006)$ \\
\hline Retrospective & 1 & $1.00(0.80$ to 1.50$)$ & - & 3 & $1.20(0.76$ to 1.91$)$ & $76.25(0.015)$ \\
\hline \multicolumn{7}{|l|}{ Time period } \\
\hline $1990 \mathrm{~s}$ & 2 & 1.19 (1.02 to 1.38$)$ & $70.1 \%(0.067)$ & 0 & - & - \\
\hline $2000 \mathrm{~s}$ & 1 & $1.00(0.80$ to 1.50$)$ & - & 2 & 1.18 (0.69 to 2.02 ) & $88.0 \%(0.004)$ \\
\hline $2010 s$ & 4 & 1.39 (1.11 to 1.74$)$ & $75.0 \%(0.007)$ & 5 & 1.07 (0.89 to 1.29$)$ & $68.1 \%(0.014)$ \\
\hline
\end{tabular}

CKD, chronic kidney disease; eGFR, estimated glomerular filtration rate; RR, risk ratio; RRT, renal replacement therapy; Scr, serum creatinine; SES, socioeconomic status.

Finally, social status itself might confer health benefits, possibly via psychosocial mechanisms, regardless of economic elements. ${ }^{79}$

Our review was rigorous in maximising its completeness and quality of evidence. To explore potential confounders, we conducted subgroup and sensitivity analyses to distinguish and diminish heterogeneity. Substantial heterogeneities were detected across the studies analysed and could not be effectively eliminated even in subgroups. The heterogeneities across countries may have been because of differences in economic or healthcare systems, and income distribution. This paper is the first attempt, to our knowledge, to include all the specific determinants of SES and elements of CKD when studying the associations between these two issues. It is in line with the view that association studies should not rely on just one indicator of SES, as each one represents a different causal process or pathway and they should not be used interchangeably. ${ }^{80}$ The population in our meta-analysis covered more geographic areas, national income levels and CKD definitions than the previous meta-analysis. ${ }^{5}$ We also adjusted the results for CKD-related healthcare access and health-related behaviours to explore clearer associations and possible mechanisms than socioeconomic indicators alone could provide. Our study reflects the global population (North America, Europe, Asia-Pacific Region, Latin America and Africa), including regions with different economic and social development levels (developed countries and low-income and middle-income countries).
This paper has several limitations. First, income, education level, occupation and the combined index were defined and classified differently in the studies analysed. Second, the definition of CKD also varied, which may lead to overdispersion of the estimated effects. Third, there might have been some selection bias in the study samples. For example, in some studies, subjects were recruited from enterprises or factories that offered physical examinations for employees. These subjects might therefore have better overall health than the general population. Finally, few studies explored the association between occupation and $\mathrm{CKD}$, or with CKD incidence as an outcome.

Most studies on the association between SES and CKD prevalence were cross-sectional and not fully adjusted for disease-related risk factors including access to healthcare (insurance or routine healthcare visits), and health-related behaviours other than smoking and alcohol consumption (such as diet, physical activity or sedentary time). The case-control or cohort studies often assessed exposure and covariates just once during follow-up, and did not fully capture the biological mechanism governing disease progression. This warrants more exploration of the changes in comorbid conditions and figures set as outcomes, and the association between continuous variables.

\section{CONCLUSION}

Several individual indicators of SES were associated with the prevalence and progression of CKD. Lower income was 
associated with prevalence and progression, but the effects of education, occupation and overall status were inconsistent. Risk estimates differed by national income levels, geographic locations and adjustment level. Our findings may be useful in developing more effective CKD prevention programme among socioeconomically disadvantaged populations.

\section{What is already known on this subject}

Individuals with lower socioeconomic status may be more likely to suffer from chronic kidney disease (CKD). This disease is one of the major public health concerns of the 21st century because of its high prevalence, mortality and social cost. Previous studies have obvious limitations including vague and variable definitions of socioeconomic status, because of the multidimensional nature of the concept, and biased results that cannot be generalised more widely because of country-specific and region-specific socioeconomic background.

\section{What this study adds}

This study is a first effort to quantitatively evaluate associations between CKD and key indicators of socioeconomic status, including income, educational attainment, occupation and a comprehensive index. Subgroup and sensitivity analyses were used to explore how associations were affected by other factors, including study locations and times, adjustment for other factors and national economic background. These may help in developing more effective kidney disease prevention programme for disadvantaged populations.

Contributors XZ and JL conceived the study. JL and ST extracted the data. XZ, $\mathrm{JL}$ and $\mathrm{HGH}$ analysed the results and drafted the manuscript. HGH and $\mathrm{YL}$ assisted with the statistical analyses and edited the manuscript. YL and PF refined the study design and contributed to supervision. Each author contributed important intellectual content during the manuscript drafting or revision and accepts accountability for the overall work by ensuring that questions pertaining to the accuracy or integrity of any portion of the work are appropriately investigated and resolved.

Funding This work was partially supported by the international cooperation project (2016HH0069) funded by the Science and Technology Department of Sichuan Province, China.

Competing interests None declared.

Provenance and peer review Not commissioned; externally peer reviewed.

(c) Article author(s) (or their employer(s) unless otherwise stated in the text of the article) 2018. All rights reserved. No commercial use is permitted unless otherwise expressly granted.

\section{REFERENCES}

1 Hallan SI, Coresh J, Astor BC, et al. International comparison of the relationship of chronic kidney disease prevalence and ESRD risk. J Am Soc Nephrol 2006;17:2275-84

2 Zhang L, Wang F, Wang L, et al. Prevalence of chronic kidney disease in China: a crosssectional survey. Lancet 2012;379:815-22.

3 Coresh J, Selvin E, Stevens LA, et al. Prevalence of chronic kidney disease in the United States. JAMA 2007;298:2038-47.

4 Lee S, Lee S, Harada K, et al. Relationship between chronic kidney disease with diabetes or hypertension and frailty in community-dwelling Japanese older adults. Geriatr Gerontol Int 2016;57.

5 Vart P, Gansevoort RT, Joosten MM, et al. Socioeconomic disparities in chronic kidney disease: a systematic review and meta-analysis. Am J Prev Med 2015;48:580-92.

6 Schäfer I, Hansen H, Schön G, et al. The influence of age, gender and socio-economic status on multimorbidity patterns in primary care. First results from the multicare cohort study. BMC Health Serv Res 2012;12:89.

7 Crews DC, Gutiérrez OM, Fedewa SA, et al. Low income, community poverty and risk of end stage renal disease. BMC Nephrol 2014;15
8 Bruce MA, Beech BM, Crook ED, et al. Association of socioeconomic status and CKD among African Americans: the Jackson Heart Study. Am J Kidney Dis 2010;55:1001-8

9 Plantinga LC. Socio-economic impact in CKD. Nephrol Ther 2013:9:1-7.

10 Krieger N, Williams DR, Moss NE. Measuring social class in US public health research: concepts, methodologies, and guidelines. Annu Rev Public Health 1997:18:341-78.

11 Uthman OA, Jadidi E, Moradi T. Socioeconomic position and incidence of gastric cancer: a systematic review and meta-analysis. J Epidemiol Community Health 2013;67:854-60.

12 Manrique-Garcia E, Sidorchuk A, Hallqvist J, et al. Socioeconomic position and incidence of acute myocardial infarction: a meta-analysis. J Epidemiol Community Health 2011;65:301-9.

13 Stroup DF, Berlin JA, Morton SC, et al. Meta-analysis of observational studies in epidemiology: a proposal for reporting. Meta-analysis Of Observational Studies in Epidemiology (MOOSE) group. JAMA 2000;283:2008-12.

14 Wolf G, Busch M, Muller N, et al. Association between socioeconomic status and rena function in a population of German patients with diabetic nephropathy treated at a tertiary centre. Nephrology Dialysis Transplantation 2011;26:4017-23.

15 Vart P, Gansevoort RT, Crews DC, et al. Mediators of the association between low socioeconomic status and chronic kidney disease in the United States. Am J Epidemiol 2015;181:385-96.

16 Hossain MP, Palmer D, Goyder E, et al. Association of deprivation with worse outcomes in chronic kidney disease: findings from a hospital-based cohort in the United Kingdom. Nephron Clin Pract 2012:120:c59-c70.

17 So BH, Methven S, Hair MD, et al. Socio-economic status influences chronic kidney disease prevalence in primary care: a community-based cross-sectional analysis. Nephrol Dial Transplant 2015;30:1010-7.

18 Merkin SS, Coresh J, Diez Roux AV, et al. Area socioeconomic status and progressive CKD: the Atherosclerosis Risk in Communities (ARIC) Study. Am I Kidney Dis 2005:46:203-13

19 Merkin SS, Diez Roux AV, Coresh J, et al. Individual and neighborhood socioeconomic status and progressive chronic kidney disease in an elderly population: The Cardiovascular Health Study. Soc Sci Med 2007:65:809-21.

20 Ward MM. Socioeconomic status and the incidence of ESRD. Am J Kidney Dis 2008:51:563-72.

21 Agency for Healthcare Research and Quality, US Department of Health and Human Services. 2010 National healthcare quality and disparities reports. Rockville, MD: Agency for Healthcare Research and Quality, 2011.

22 Agardh E, Allebeck P, Hallqvist J, et al. Type 2 diabetes incidence and socioeconomic position: a systematic review and meta-analysis. Int J Epidemiol 2011:40:804-18.

23 Akrawi DS, Li X, Sundquist J, et al. End stage renal disease risk and neighbourhood deprivation: a nationwide cohort study in Sweden. Eur J Intern Med 2014;25:853-9.

24 Al-Qaoud TM, Nitsch D, Wells J, et al. Socioeconomic status and reduced kidney function in the Whitehall II Study: role of obesity and metabolic syndrome. Am J Kidney Dis 2011:58:389-97.

25 Fored CM, Ejerblad E, Fryzek JP, et al. Socio-economic status and chronic renal failure: a population-based case-control study in Sweden. Nephrol Dial Transplant 2003; 18:82-8

26 Tohidi M, Hasheminia M, Mohebi R, et al. Incidence of chronic kidney disease and its risk factors, results of over 10 year follow up in an Iranian cohort. PLoS One 2012;7:e45304.

27 DerSimonian R, Laird N. Meta-analysis in clinical trials. Control Clin Trials 1986;7:177-88.

28 Blettner M, Sauerbrei W, Schlehofer B, et al. Traditional reviews, meta-analyses and pooled analyses in epidemiology. Int J Epidemiol 1999;28:1-9.

29 Higgins JP, Thompson SG. Quantifying heterogeneity in a meta-analysis. Stat Med 2002;21:1539-58.

30 Higgins JP, Thompson SG, Deeks JJ, et al. Measuring inconsistency in meta-analyses. BMJ 2003;327:557-60.

31 Normand SL. Meta-analysis: formulating, evaluating, combining, and reporting. Stat Med 1999:18:321-59.

32 Egger M, Davey Smith G, Schneider M, et al. Bias in meta-analysis detected by a simple, graphical test. BMJ 1997;315:629-34.

33 Begg CB, Mazumdar M. Operating characteristics of a rank correlation test for publication bias. Biometrics 1994:50:1088-101.

34 Seck SM, Doupa D, Gueye L, et al. Prevalence of chronic kidney disease and associated factors in senegalese populations: a community-based study in saint-louis. Nephrourol Mon 2014;6.

35 Flessner MF, Wyatt SB, Akylbekova EL, et al. Prevalence and awareness of CKD among African Americans: the Jackson Heart Study. Am J Kidney Dis 2009;53:238-47.

36 Crews DC, Charles RF, Evans MK, et al. Poverty, race, and CKD in a racially and socioeconomically diverse urban population. Am J Kidney Dis 2010;55:992-1000.

37 Choi Al, Weekley CC, Chen SC, et al. Association of educational attainment with chronic disease and mortality: the Kidney Early Evaluation Program (KEEP). Am J Kidney Dis 2011;58:228-34.

38 Fisher MA, Taylor GW, Shelton BJ, et al. Periodontal disease and other nontraditiona risk factors for CKD. Am J Kidney Dis 2008;51:45-52. 
$39 \mathrm{Kim} \mathrm{TH}$, Lee MJ, Yoo KB, et al. Association of demographic and socioeconomic factors with risk factors for chronic kidney disease. J Prev Med Public Health 2015;48:170-7

40 Lin MY, Chiu YW, Lee CH, et al. Factors associated with CKD in the elderly and nonelderly population. Clin J Am Soc Nephrol 2013;8:33-40.

41 Liu Q, Li Z, Wang H, et al. High prevalence and associated risk factors for impaired renal function and urinary abnormalities in a rural adult population from southern China. PLoS One 2012;7:e47100.

42 Seck SM, Doupa D, Guéye L, et al. Chronic kidney disease epidemiology in northern Senegal: a cross-sectional study. Iran J Kidney Dis 2014;8:286-91.

43 White SL, McGeechan K, Jones M, et al. Socioeconomic disadvantage and kidney disease in the United States, Australia, and Thailand. Am J Public Health 2008:98:1306-13.

44 Xue L, Lou Y, Feng $X$, et al. Prevalence of chronic kidney disease and associated factors among the Chinese population in Taian, China. BMC Nephrol 2014;15:205.

45 Hsieh CF, Huang SL, Chen CL, et al. Increased risk of chronic kidney disease among users of non-prescribed Chinese herbal medicine in Taiwan. Prev Med 2012;55:155-9.

46 Su SL, Lin C, Kao S, et al. Risk factors and their interaction on chronic kidney disease: a multi-centre case control study in Taiwan. BMC Nephrol 2015;16:83.

47 Barreto SM, Ladeira RM, Duncan BB, et al. Chronic kidney disease among adult participants of the ELSA-Brasil cohort: association with race and socioeconomic position. J Epidemiol Community Health 2016;70:380-9.

48 Chudek J, Wieczorowska-Tobis K, Zejda J, et al. The prevalence of chronic kidney disease and its relation to socioeconomic conditions in an elderly Polish population: results from the national population-based study PolSenior. Nephrology Dialysis Transplantation 2014;29:1073-82.

49 Fraser SD, Roderick PJ, Aitken G, et al. Chronic kidney disease, albuminuria and socioeconomic status in the health surveys for England 2009 and 2010. J Public Health 2014;36:577-86.

50 Guessous I, Ponte B, Marques-Vidal P, et al. Clinical and biological determinants of kidney outcomes in a population-based cohort study. Kidney Blood Press Res 2014:39:74-85.

51 Suarez JJ, Isakova T, Anderson CA, et al. Food access, chronic kidney disease, and hypertension in the U.S. Am J Prev Med 2015;49:912-20.

52 Vart P, Gansevoort RT, Coresh J, et al. Socioeconomic measures and CKD in the United States and The Netherlands. Clin J Am Soc Nephrol 2013;8:1685-93.

53 Amato D, Alvarez-Aguilar C, Castaneda-Limones R, et al. Prevalence of chronic kidney disease in an urban Mexican population. Kidney Int 2005;68(SUPPL. 97):S11-S17.

54 Drey $\mathrm{N}$, Roderick $\mathrm{P}$, Mullee $\mathrm{M}$, et al. A population-based study of the incidence and outcomes of diagnosed chronic kidney disease. Am J Kidney Dis 2003;42:677-84.

55 Shoham DA, Vupputuri S, Kaufman JS, et al. Kidney disease and the cumulative burden of life course socioeconomic conditions: the Atherosclerosis Risk in Communities (ARIC) study. Soc Sci Med 2008;67:1311-20.

56 Martins D, Tareen N, Zadshir A, et al. The association of poverty with the prevalence of albuminuria: data from the Third National Health and Nutrition Examination Survey (NHANES III). Am J Kidney Dis 2006:47:965-71.

57 Tamrat R, Peralta CA, Tajuddin SM, et al. Apolipoprotein L1, income and early kidney damage. BMC Nephrol 2015;16:14.

58 Hsu CY, Iribarren C, McCulloch CE, et al. Risk factors for end-stage renal disease: 25year follow-up. Arch Intern Med 2009;169:342-50

59 Brancati FL, Whittle JC, Whelton PK, et al. The excess incidence of diabetic end-stage renal disease among blacks. A population-based study of potential explanatory factors. JAMA 1992:268:3079-84.
60 Couchoud C, Guihenneuc C, Bayer F, et al. Medical practice patterns and socioeconomic factors may explain geographical variation of end-stage renal disease incidence. Nephrol Dial Transplant 2012;27:2312-22.

61 Klag MJ, Whelton PK, Randall BL, et al. End-stage renal disease in African-American and white men. 16-year MRFIT findings. JAMA 1997;277:1293-8.

62 Lipworth L, Mumma MT, Cavanaugh KL, et al. Incidence and predictors of end stage renal disease among low-income blacks and whites. PLoS One 2012;7:e48407.

63 Perneger TV, Whelton PK, Klag MJ. Race and end-stage renal disease. Socioeconomic status and access to health care as mediating factors. Arch Intern Med 1995; 155:1201-8.

64 Tsai SY, Tseng HF, Tan HF, et al. End-stage renal disease in Taiwan: a case-control study. J Epidemiol 2009;19:169-76.

65 Young EW, Mauger EA, Jiang KH, et al. Socioeconomic status and end-stage renal disease in the United States. Kidney Int 1994;45:907-11.

66 Young BA, Katz R, Boulware LE, et al. Risk factors for rapid kidney function decline among African Americans: the Jackson Heart Study (JHS). Am J Kidney Dis 2016:68:229-39.

67 Mavridis D, Salanti G. How to assess publication bias: funnel plot, trim-and-fill method and selection models. Evid Based Ment Health 2014;17:30.

68 Garland JS. Elevated body mass index as a risk factor for chronic kidney disease: current perspectives. Diabetes Metab Syndr Obes 2014;7:347.

69 Eikemo TA, Bambra C, Joyce K, et al. Welfare state regimes and income-related health inequalities: a comparison of 23 European countries. Eur J Public Health 2008;18:593-9.

70 Stephan D, Gaertner S, Cordeanu EM. A critical appraisal of the guidelines from France, the UK, Europe and the USA for the management of hypertension in adults. Arch Cardiovasc Dis 2015;108(8-9):453-9.

71 Basu S, Hassenplug JC. Patient access to medical devices-a comparison of U.S. and European review processes. N Engl J Med 2012;367:485-8.

72 Feinglass J, Lin S, Thompson J, et al. Baseline health, socioeconomic status, and 10-year mortality among older middle-aged Americans: findings from the health and retirement study, 1992 2002. J Gerontol B Psychol Sci Soc Sci 2007;62:S209-S217.

73 Lantz PM, Golberstein E, House JS, et al. Socioeconomic and behavioral risk factors for mortality in a national 19-year prospective study of U.S. adults. Soc Sci Med 2010:70:1558-66.

74 Rask K, O'Malley E, Druss B, et al. Impact of socioeconomic, behavioral and clinical risk factors on mortality. J Public Health 2009:31:231-8.

75 Cutler DM, Lleras-Muney A. Education and health: evaluating theories and evidence. In: Schoeni RF, House JS, Kaplan GA, eds. Making Americans healthier: social and economic policy as health policy. russell sage foundation, 2008:29-59. p.

76 Hiltunen LA. Are there associations between socio-economic status and known diabetes in an elderly finnish population? Cent Eur J Public Health 2005;13:187-90.

77 Morikawa Y, Nakagawa H, Miura K, et al. Effect of shift work on body mass index and metabolic parameters. Scand J Work Environ Health 2007;33:45-50.

78 Vasan RS, Larson MG, Leip EP, et al. Assessment of frequency of progression to hypertension in non-hypertensive participants in the framingham heart study: a cohor study. Lancet 2001;358:1682-6.

79 Fitzpatrick R. Social status and mortality. Ann Intern Med 2001;134:1001-3.

80 Geyer S, Hemström O, Peter R, et al. Education, income, and occupational class canno be used interchangeably in social epidemiology. Empirical evidence against a common practice. J Epidemiol Community Health 2006;60:804-10.

81 Singh NP, Ingle GK, Saini VK, et al. Prevalence of low glomerular filtration rate, proteinuria and associated risk factors in North India using cockcroft-gault and modification of diet in renal disease equation: an observational, cross-sectional study. BMC Nephrol 2009;10:4. 